\title{
Public Education
}

Expenditures and Private

School Enrollment

\author{
FERNANDA ESTEVAN
}

Working PAPER SERIES № 2014-14 
DEPARTMENT OF ECONOMICS, FEA-USP

WORKING PAPER № 2014-14

\title{
Public Education Expenditures and Private School Enrollment
}

Fernanda Estevan (festevan@usp.br)

\begin{abstract}
:
In this paper, I investigate whether increases in public education expenditures lead to reductions in private school enrollment. In order to deal with the endogeneity of public expenditures, I use as a natural experiment the 1998 FUNDEF reform in Brazil that caused exogenous variations in local public school funding. Using data from Brazilian School and Population Censuses, I show that public education expenditures increases are associated with reductions in the share of private school enrollment for Grade 1. However, the effect is smaller for Grades 2 to 4 , which is consistent with the existence of costs associated with switching schools
\end{abstract}

Keywords: private education, public education, public expenditures, school choice, crowding out.

JEL Codes: H42, H52, I22. 


\title{
Public Education Expenditures and Private School Enrollment*
}

\author{
Fernanda Estevan ${ }^{\dagger}$
}

\begin{abstract}
In this paper, I investigate whether increases in public education expenditures lead to reductions in private school enrollment. In order to deal with the endogeneity of public expenditures, I use as a natural experiment the 1998 FUNDEF reform in Brazil that caused exogenous variations in local public school funding. Using data from Brazilian School and Population Censuses, I show that public education expenditures increases are associated with reductions in the share of private school enrollment for Grade

1. However, the effect is smaller for Grades 2 to 4 , which is consistent with the existence of costs associated with switching schools.
\end{abstract}

Keywords: private education, public education, education quality, public expenditures, school choice, school inputs, crowding out.

JEL: H52, I22.

*I would like to thank the Ministry of Education, the National Treasury, the State Treasuries, and IPEA for providing me with the data used in this analysis. I thank Jean-Marie Baland, Pierre Brochu, David de la Croix, Randall Ellis, André C. Martínez Fritscher, Thomas Gall, Jean Hindriks, Kevin Lang, Jean-François Maystadt, Louis-Philippe Morin, Walter Steingress, Eric Strobl, Alejandra Traferri, Miguel Urquiola, Vincent Vandenberghe, Eric Verhoogen, and Marian Vidal-Fernández for very useful comments at different stages of this research. I also thank Marie-Hélène Brière and Ruth Bradley-St-Cyr for proofreading. This paper was presented at the Doctoral Workshop at Université catholique de Louvain, the EUDN Doctoral Workshop at Oxford University, EEA 2011, NEUDC 2011, the Microeconomics Dissertation Workshop at Boston University, IPEA, FGV-SP, and the University of Ottawa and has greatly benefited from their participants' suggestions. I also acknowledge the Canadian Journal of Economics, Canadian Economics Association, and Wiley-Blackwell for the useful and constructive revision process. I started this research while visiting CERGE-EI, Prague, under a Marie-Curie Host Fellowships for Early Stage Training (EST) in Public Policy, Market Organization and Transition Economies. Financial support from this fellowship is fully acknowledged. A first draft of this paper was written while I was a visiting PhD research scholar at the Institute for Economic Development at Boston University and most of the revisions were made while I was affiliated to the Department of Economics at the University of Ottawa, Canada. All remaining errors are mine. Phone: (+55) 11 2648-6070. Email: festevan@usp.br.

${ }^{\dagger}$ Department of Economics, University of Sao Paulo, Avenida Professor Luciano Gualberto, 908 - Cidade Universitária - São Paulo - SP - Brazil - CEP: 05508-010; Phone: +55 1126486070 - Fax: +55 113814 3814, e-mail address: festevan@usp.br. 


\section{Introduction}

The improvement of public school quality is a leading issue for developing countries, as many of them are approaching universal primary education. There is much evidence suggesting that education systems in developing countries are deficient and lack basic inputs (e.g., Harbison and Hanushek, 1992; Lockheed and Verspoor, 1991). Accordingly, the literature has largely focused on evaluating the effectiveness of public policies in raising school expenditures and school quality and, ultimately, human capital. ${ }^{1}$

However, the effect of these public policies on household investment in private education has been largely ignored. This paper investigates one prominent mechanism through which public expenditures in education quality may crowd out private investment, namely the choice of public versus private schooling.

Understanding the impact of increases in public school expenditures on private school enrollment is essential for policy purposes. Public policies may underestimate the financial need in terms of investment in education if they ignore the possible increase in the number of students opting for public schools. By the same token, policy evaluations may overestimate the impact of such policies on total education investment, by ignoring the crowding out of private education spending. Also, any observed increase in public enrollment may not completely translate into an increase in total enrollment if a portion of it was simply shifted from the private system. On a related note, public education policies are typically justified on redistributive grounds. Therefore, it is important to understand who are the real beneficiaries of such policies.

Moreover, evaluations of the effect of policies targeting school quality on student outcomes can be biased if they do not take into account that these policies can also affect the student composition. If public schools attract pupils previously enrolled in private schools, who are on average richer, test scores may increase due to the improvement of the quality of students (i.e., a selection effect) rather than exclusively through the effect of the policy. Thus, a policy evaluation that does not take into account the composition effect will overestimate the effects of the policy.

Although increasing public school expenditures may increase public school enrollment-some students who would have chosen private education now choose public education - there are two mitigating factors that must be accounted for: First, parents may still choose private education to avoid having their child interact with poorer students. They may do so to benefit from the peer effects of richer children or simply due to social prejudice. This phenomenon is especially likely in societies, such as Brazil, characterized by large levels of income inequality. Second, the cost of switching schools may be prohibitive (e.g., "logistics" costs for the parents and emotional costs for the child). Both of these factors would dampen the impact of increased public school expenditures on public school enrollment.

\footnotetext{
${ }^{1}$ Throughout the paper, the underlying assumption is that increases in public school expenditures translate into improvements in school quality. For a comprehensive discussion on school quality, see Hanushek (2006) and Hanushek and Rivkin (2006).
} 
Previous attempts to analyze the impact of public school expenditures on the demand for private education have recognized the endogeneity problems associated with public expenditures (e.g., Goldhaber, 1999). Private school enrollment may lower public expenditures on education, due to the decrease in political support for public education expenditures caused by a high proportion of households opting out of public education. $^{2}$

Using election years as instruments, Jimenez and Sawada (2001) show that the expansion of the public education sector in the Philippines reduced private secondary school enrollment, but not private primary school enrollment. ${ }^{3}$ More recently, Muralidharan and Kremer (2008) show that private schools in India are disproportionately located in villages characterized by the low quality of public schools. Lucas and Mbiti (2012) show evidence of "rich flight" from public schools following the increase in public school enrollment (without a corresponding increase in funding) caused by the abolition of school fees in Kenya in 2003. Along the same lines, Glick and Sahn (2006) and Alderman et al. (2001) present evidence that school quality affects schooling demand in both Madagascar and Pakistan. ${ }^{4}$

I take advantage of the 1998 Brazilian FUNDEF (Fund for the Maintenance and Development of the Fundamental Education and Valuing of Teaching $)^{5}$ reform, an exogenous source of variation in local education budgets, to test the effect of increases in public school expenditures on private enrollment in the Brazilian primary education system (i.e., Grades 1 to 4). The advantage of focusing on Grades 1 to 4 is that primary public schools are available in all municipalities. Therefore, enrollment in private schools can be considered a choice, rather than a consequence of the absence of public alternatives.

Using the approach developed by Kosec (2011), I can establish and quantify the causal relationship between increases in public school expenditures and private school enrollment. I also propose a simple method for investigating the propensity of households to choose private school in environments characterized by late school entry and high repetition rates, as is the case in Brazil and in many other developing countries.

By comparing 1997 and 1999, I concentrate on the short-term impact of FUNDEF. This has the advantage of avoiding confounding effects from other policies implemented in subsequent years. ${ }^{6}$ The results indicate that the reform led to a decrease in the share of private enrollment over the primary school-age population

\footnotetext{
${ }^{2}$ The literature on the political economy of public education expenditures is extensive (e.g., Stiglitz, 1974; Epple and Romano, 1996).

${ }^{3}$ Using data on 21 low-income countries, Filmer (2007) simulates the impact of school construction on enrollment. He shows that the effect is positive but relatively small and suggests that improving school quality may be more effective.

${ }^{4}$ In a developed country context, Couch et al. (1993) find a negative relation between private school enrollment and per student spending in the public system, using North Carolina county-level data. They also argue that parents choose private school to avoid their child having classmates who are black or from low-income households. Using a panel of New York State school districts, Goldhaber (1999) shows that increases in public (per pupil) expenditure have a significant and negative effect on private school enrollment rates. He does not, however, find evidence of decreased tax support for public schools.

${ }^{5}$ Fundo de Manutenção e Desenvolvimento do Ensino Fundamental e de Valorização do Magistério, in Portuguese.

${ }^{6}$ A number of other reforms were implemented in Brazil a few years after FUNDEF, such as Bolsa Escola in 2001, a conditional cash transfer (CCT) program. A pilot CCT program was in place in the capital, Brasília, in 1997. Therefore, I exclude Brasília from the analysis.
} 
that is larger for Grade 1 relative to Grades 2 to 4, suggesting the existence of switching costs. In the municipalities that were net recipients from FUNDEF, a one standard deviation increase of the FUNDEF impact variable, which roughly corresponds to a $40 \%$ increase in the education budget, ${ }^{7}$ led to a 0.56 percentage point decrease in private school enrollment in Grade 1. Given the sample average, this corresponds to a reduction in private school enrollment of $10.4 \%$ for Grade 1 . In Grades 2 to 4 , the decrease is smaller, corresponding to a decrease of around 5\% and statistically significant only at the $10 \%$ level. Accordingly, the availability of private schools decreased by $3 \%$ in these municipalities. The same effects are not observed in municipalities that were net contributors to FUNDEF. These results are robust to the introduction of controls for population, mean wage earnings, and employment rate. I also present evidence that suggests that increases in public school expenditures had a positive effect on net school attendance rates in Brazil. ${ }^{8}$

The remainder of the paper is organized as follows. In Section 2, I describe the main features of the Brazilian primary education system and the FUNDEF reform. The data and descriptive statistics are presented in Section 3, and the empirical strategy is described in Section 4. The estimation results and some robustness checks are discussed in Section 5, and Section 6 concludes.

\section{The Brazilian Education System and the FUNDEF Reform}

Primary education is offered by public and private schools in Brazil. During the years under analysis, it comprised four grades. ${ }^{9}$ Municipalities and states run independent school systems, so public schools are either state or municipal schools. ${ }^{10}$ In $1997,9 \%$ of the more than 20 million students enrolled in primary education were attending private schools. The share of private enrollment in primary education varies significantly from one state to the other, ranging from $1.6 \%$ to $21.9 \%$ in $1997 .^{11}$ In $1997,2,120$ municipalities had at least one private primary school (38\% of the 5,507 municipalities). Private schools do not receive public funds and are mainly financed by tuition fees, which are tax deductible.

The 1988 Brazilian Constitution intended to guarantee a minimum education budget by imposing that states and municipalities invest at least $25 \%$ of their tax and transfer revenues in their respective public education systems. Not surprisingly, this rule generated large inequalities between public schools by rendering the size of their education budget dependent on municipal or state revenue. As a result, there were large disparities in public education expenditures per student across states and within state per system (state or

\footnotetext{
${ }^{7}$ As will be shown in Section 3, a one standard deviation of the FUNDEF variable corresponds to a $65.3 \%$ increase in the portion of the education budget affected by the reform, which is $60 \%$.

${ }^{8}$ This is in line with the results typically obtained in the literature (e.g., Lavy, 1996; Bommier and Lambert, 2000; Handa, 2002; Paxson and Schady, 2002).

${ }^{9}$ In 2003 primary education was increased to five grades.

${ }^{10}$ Brazil is composed of 26 states divided into municipalities, and one federal district. In 1997 there were 5,507 municipalities.

${ }^{11}$ Detailed information by state on private enrollment and education expenditures by state can be obtained from the author upon request.
} 
municipal).

The 1998 FUNDEF reform aimed at improving the distribution and use of resources inside each state for primary and low secondary public education, i.e., Grades 1 to 8 . The $25 \%$ minimum requirement was still maintained. However, only $10 \%$ of the tax and transfer revenue was still directly invested in their respective education systems, i.e., was left untouched by the reform. The remaining $15 \%$ of the four main taxes and transfers were directed into a fund created in each of the 26 states. The amount collected in each fund was then redistributed to the municipalities and the state itself, according to the number of students enrolled in Grades 1 to 8 in their respective systems the previous year. Moreover, the federal government provided additional funds for those states whose total FUNDEF resources divided by the number of students fell below the established minimum level. ${ }^{12}$

In addition to being redistributive, the FUNDEF reform imposed strict rules on how the resources received from the fund should be spent. The revenue received from FUNDEF had to be spent exclusively on Grades 1 to 8 . Also, $60 \%$ of the resources received from the fund had to be spent on teacher wages and, in the first five years, could be used to increase teacher qualifications. The remaining $40 \%$ of FUNDEF was to be spent on teacher training, school facilities, and any materials or equipment related to teaching. ${ }^{13}$

Table A1 provides the distribution of public school enrollment in the state and municipal system for each state. There are large variations in terms of enrollment in municipal versus state schools across the country. Table A1 also summarizes the aggregate financial impact of the FUNDEF reform in each state by system (municipal and state). In most of the cases, the aggregate balances of the municipal and state systems sum to zero (sum of columns (e) and (h)), since the reform was meant to redistribute resources within the state. The final balance is positive only in those states that received federal funds.

However, even when the state aggregate balance is zero, there are significant variations in the impact of FUNDEF at the municipal level, as will be shown in Section 4. State and municipal schools are unevenly distributed in different municipalities and states, mainly for historical reasons. Therefore, the impact of FUNDEF on a given municipality may be very different from the aggregate impact on the state to which it belongs. ${ }^{14}$

\footnotetext{
${ }^{12}$ In 1998 the minimum annual FUNDEF value per student was established at $\mathrm{R} \$ 315.00$, or US $\$ 272.00$ (in 1998 , US $\$ 1=\mathrm{R} \$ 1.16$ on average). Only six states received additional resources from the federal government because they were below the minimum level per student. These states were: Pará, Bahia, Ceará, Maranhão, Pernambuco, and Piauí and they account for 1,364 municipalities, or 690 if one restricts the sample to municipalities with a private school in 1999.

${ }^{13}$ There is evidence that FUNDEF is correlated with a decrease in the proportion of teachers with only primary education, and with some school quality indicators such as the presence of electricity, water, and science laboratory (see Estevan, 2009, for more details.)

${ }^{14}$ For instance, in the state of Acre (first line in Table A1), the aggregate balance is equal to zero. However, those municipalities with a predominance of municipal schools were positively impacted by the FUNDEF reform, while the impact was negative when mostly state schools were present in the municipality. In general, municipalities may have both state and municipal schools so that the impact in both systems has to be taken into account (see Section 4 for more details on how I combine the impact on the two systems).
} 
More generally, a municipality's (or state's) balance from FUNDEF in 1998 is a function of the FUNDEF redistribution mechanism, its school enrollment in 1997, and the tax revenue in 1998. Since the redistribution mechanism was defined at the federal level, and was uniform across the country, one can reasonably assume that it was independent of the preferences of the states and municipalities. Moreover, the FUNDEF rule is unrelated to the proportion of students enrolled in private schools, at least to the extent that this may reduce political support for public education.

Due to the timing of the FUNDEF reform, enrollment in 1997 can also be considered to be exogenous. The FUNDEF law was first instituted in September 1996 (Constitutional Amendment no. 14) and stipulated that the amounts transferred to states and municipalities would be based on enrollment, without any further precision. However, the regulation that FUNDEF transfers would be based on the previous year's enrollment only came into effect at the end of June 1997 (Act no. 2.264). This was five months after the beginning of the school year (which runs from February to December), and three months after the School Census (which is the data source used for enrollment figures) had been conducted. Thus, by the time FUNDEF rules were defined, municipalities could no longer react to the prospect of its implementation in 1998 by inflating enrollment in 1997.

Finally, the 1998 tax revenue could potentially be endogenous due to omitted variable bias. For instance, an increase in a municipality's or state's unobserved macroeconomic variable could lead to higher taxes and transfers, increasing FUNDEF revenues, but could also directly affect the share of private school enrollment. In order to isolate the exogenous component of the FUNDEF reform, I instrument the FUNDEF variable, to be described in Section 4, by the simulated FUNDEF variable, which is calculated in the same way, but uses enrollment and tax revenues for 1997. This approach is similar to the one adopted by Kosec (2011) and allows me to isolate the exogenous impact of the FUNDEF reform.

\section{Data}

In order to investigate the impact of the FUNDEF reform on private school enrollment, I combine four data sources: School Census data, Population Census and Count data, National and State Treasury data, and the Annual Social Information Report. ${ }^{15}$

The Brazilian School Census contains administrative information for each public and private school in

the country. ${ }^{16}$ It provides grade-specific enrollment data at the school level. Since the financial impact of FUNDEF is observed at the administrative unit level (and not at the school level), I aggregate the School

\footnotetext{
${ }^{15}$ Appendix $\mathrm{B}$ provides a more detailed description of the data and the variables.

${ }^{16}$ The information is provided annually by the school principal in a questionnaire collected by Instituto Nacional de Estudos e Pesquisas Educacionais Anísio Teixeira (INEP), National Institute for Education Studies and Research Anísio Teixeira, www.inep.gov.br, a federal institution related to the Ministry of Education.
} 
Census data to the municipal level.

The 2000 Population Census collected by the Brazilian Institute of Geography and Statistics ${ }^{17}$ contains information on population by age in each municipality. Using that data, I calculate the grade-specific primary school-age population and the population aged 15 to 64 for 1997 and $1999 .{ }^{18}$ In order to control for different fertility trends of high and low income households, I use data on the number of children per household income level. ${ }^{19}$ Finally, I use information on the number of children aged 7 to 9 attending school from both the 1996 Population Count and the 2000 Population Census to calculate net attendance rates. ${ }^{20}$

The Brazilian National and State Treasuries ${ }^{21}$ data contain information on tax and transfer revenues per state and per municipality, which makes it possible to calculate their contribution to and revenue from FUNDEF. Using 1997 tax and transfer revenue data, I also calculate a simulated measure of the financial impact of FUNDEF at the municipal level to be used as an instrument, as discussed in Section 2.

The Annual Social Information Report ${ }^{22}$ contains (formal) employment and wage earnings information for the universe of establishments in Brazil in all branches of economic activity. I use data on mean earnings in December and number of employees aggregated at the municipality level for 1997 and 1999 to control for local economic performance. Using the data on number of employees I calculate the employment rate by using the population aged 15-64 obtained from the 2000 Population Census, as explained above.

Table A2 provides a general characterization of the Brazilian primary education system for 1997 and 1999, one year before and after the FUNDEF reform. The total number of schools offering primary education declined between 1997 and 1999 due to the decrease in the number of public schools. The data (not presented here) show that the decrease was much more significant in municipalities losing resources with FUNDEF. In contrast, the number of private schools slightly increased over the period. Despite these changes, enrollment in public schools increased between 1997 and 1999, and enrollment in private schools decreased. Table A2 also presents information on the primary school-age population. The decline in the number of children aged 7 to 10 (i.e., in the primary school-age population) in 1999 is consistent with the reduction in fertility rates in Brazil. ${ }^{23}$ Moreover, the number of children enrolled in primary school is much larger than the primary school-age population. According to the 1999 School Census, the age-by-grade distortion rate is $39.2 \%$

\footnotetext{
${ }^{17}$ Instituto Brasileiro de Geografia e Estatística (IBGE), www.ibge.gov.br.

${ }^{18}$ For example, to compute the number of children that should be in Grade 1, i.e., aged 7 in 1997 I use the number of children who were 10 in 2000 since they would have been 7 in 1997 . Similar exercises are done for the remaining grades and for 1999. For the population aged 15 to 64 , I use the age group 18 to 67 (in 2000) for 1997 and the age group 16 to 65 (in 2000 ) for 1999. The assumption is that there were no significant population changes in these age groups due to migration or mortality between 1997 and 2000. I discuss the validity of this assumption in further details in Section 5.

${ }^{19}$ The 2000 Population Census contains information on the number of children per household income for specific age groups. From the 2000 data, I use the 7 to 9 age group for 1999, and the 10 to 14 age group for 1997 . The assumption is that the income level of these age groups followed similar patterns between 1997 and 2000 .

${ }^{20}$ The advantage of this data source is that the information is provided by households, and not by schools, which might possibly inflate enrollment figures in an attempt to attract additional funds from FUNDEF in the following year.

${ }^{21}$ Secretaria do Tesouro Nacional (STN), www.tesouro.fazenda.gov.br.

${ }^{2}$ Relação Anual de Informações Sociais (RAIS), http://laborsta.ilo.org/applv8/data/SSM2/E/BR.html.

${ }^{23} \mathrm{As}$ far as this reduction is uncorrelated with FUNDEF, this should not affect the results.
} 
in primary education. This confirms that the discrepancy between the Population Census and the School Census numbers is due to the fact that many children enrolled in school are older than the normal school age. However, there are also primary school age children out of school. According to the 1996 Population Count, $9 \%$ of children aged 7 to 9 were not attending school. Table A2 also shows that the gross enrollment rate has substantially increased in the period coinciding with the FUNDEF reform.

Table 1 presents descriptive statistics for 1997 and 1999 for all the sub-samples of municipalities with data available used in the analysis. For the full sample, there was a significant decrease in the share of private education in almost all primary school grades, even though the proportion of municipalities with a private school has increased from $40.5 \%$ to $42.9 \%$. While there were no significant changes in the average municipal population, the proportion of children living in high-income households decreased in 1999 over 1997, possibly reflecting the lower fertility rate among high-income households. The mean earnings increased over the period from 302 to 322 reais (in nominal terms), while the employment rate increased by $3 \%$. Table 1 also shows descriptive statistics for the sub-samples of net recipients and net contributors to FUNDEF, defined based on the simulated impact of the FUNDEF reform to be explained below. The data indicates that the decrease in the share of private enrollment is only significant in those municipalities that were net recipients of FUNDEF (for some grades). Apart from that, the trends in the other control variables, such as mean earnings, population and employment rate, are very similar in these sub-samples.

\section{Empirical Model}

The main goal of the paper is to investigate the impact of the FUNDEF reform on the choice of private versus public school. In order to control for the size of the student population, the dependent variable is calculated as the share of private enrollment over school-age population in each municipality. ${ }^{24}$ Assuming that children previously out of school have a zero probability of choosing private education, then this share correctly measures the household propensity to choose private schools, even in the presence of variations in gross enrollment rates. The school-age population is also unaffected by possible inflated public enrollment

\footnotetext{
${ }^{24}$ Alternatively, this share could be calculated over total enrollment in each municipality (i.e., public and private). However, such a measure could be misleading if there was an increase in gross enrollment, as in Brazil (see Table A2). As children out of school (in the correct age group or not) typically come from lower income backgrounds and have limited access to private schools, it seems reasonable to assume that they would mostly enroll in public schools once they enter the school system. As a consequence, the share of private enrollment over total enrollment would decrease (because public enrollment increases), but such a reduction is unrelated to the choice of public versus private school. According to the 2000 Population Census, only $3 \%$ of children aged 7 to 9 out of school belong to high-income households (i.e., monthly per capita income larger than twice the National Minimum Wage). Using the 1999 School Census, I compute two indicators that confirm that most of the children that are older than the normal school age are enrolled in public schools. From grades 1 to 4, the age-by-grade distortion rate ranges from $34.4 \%$ to $62.4 \%$ in public schools and $6.7 \%$ to $11.9 \%$ in private schools. The median age of students in grades 1 to 4 varies from 8.3 to 12.8 years in public schools compared to 7.2 to 10.4 years in private schools.
} 
figures of municipalities trying to attract more funding from FUNDEF. ${ }^{25}$ The model presented in differenced form is:

$$
\begin{aligned}
\frac{P_{i, 99}}{C_{i, 99}}-\frac{P_{i, 97}}{C_{i, 97}} & =\beta_{0} D 1999+\beta_{1} \text { TOTIMPACT } T_{i}+\beta_{2}\left(R_{i, 99}-R_{i, 97}\right)+\beta_{3}\left(L_{i, 99}-L_{i, 97}\right)+\beta_{4}\left(M_{i, 99}-M_{i, 97}\right) \\
& +\beta_{5}\left(E_{i, 99}-E_{i, 97}\right)+\left(\varepsilon_{i, 99}-\varepsilon_{i, 97}\right)
\end{aligned}
$$

where $P_{i, t}$ is total enrollment in private schools in municipality $i$ at time $t, C_{i, t}$ is the primary school-age population, D1999 is a dummy variable equal to 1 if 1999 and 0 if 1997, TOTIMPACT $T_{i}$ is an indicator of the impact of the FUNDEF reform, $R_{i, t}$ is the share of children living in high-income households, $L_{i, t}$ is total population (measured in 100,000s), $M_{i, t}$ is mean earnings (measured in 1,000s), $E_{i, t}$ is employment rate, and $\varepsilon_{i, t}$ is the error term. The inclusion of $R_{i, t}$ is meant to capture the fact that private school pupils mostly come from high-income households, while $M_{i, t}$ controls for macro shocks that may affect household's income and is a measure of local economic performance. I also add the employment rate, $E_{i, t}$, as an additional measure of economic performance.

The variable TOTIMPACT combines the ratio of the net balance of FUNDEF to the contribution to FUNDEF in the state and municipal school systems. Thus, it measures the net balance of FUNDEF relative to the contribution to FUNDEF. The use of the change in percentage terms as opposed to absolute values is meant to better capture the impact of the reform. Indeed, the same net FUNDEF balance will have a larger or a smaller impact on the municipal budget, depending on the size of the contribution to FUNDEF (which corresponds to about $60 \%$ of the total education budget). ${ }^{26}$

More specifically, let $a \in\{m, s\}$ stand for the municipal and state system operating in municipality $i$. The impact of the FUNDEF reform in municipality $i$ is measured by: ${ }^{27}$

$$
\text { TOTIMPACT }=\sum_{a \in\{m, s\}} e_{i, 97}^{a}\left(\frac{I_{i, 98}^{a}-O_{i, 98}^{a}}{O_{i, 98}^{a}}\right),
$$

where $e_{i, 97}^{a}$ is the share of students in public education enrolled in a public school belonging to school system $a$ (municipal or state) in 1997, and $I_{i, 98}^{a}$ and $O_{i, 98}^{a}$ are the amounts that the school system $a$ has received

\footnotetext{
${ }^{25}$ There is evidence that some municipalities inflated enrollment figures following the FUNDEF reform. Audits performed by the Brazilian Ministry of Education detected 115,000 "ghost" students (Câmara dos Deputados, 2001).

${ }^{26}$ Litschig and Morrison (2013) use similar Brazilian financial data to investigate the impact of public expenditures on several socio economic outcomes for the pre-FUNDEF period (1980-1991). Instead of using the percentage change in funding, they use the change in total public funding received by the municipalities. This is justifiable since they adopt a discontinuity-based approach and therefore are comparing relatively similar municipalities, which is not the case in this paper. Kosec (2011) also uses FUNDEF revenue in absolute value, which is appropriate since her main specifications involve the effect of FUNDEF on pre-primary education spending.

${ }^{27}$ This is equivalent to calculating $(a) \times((e) /(c))+(b) \times((h) /(f))$ using Table A1, except that the data in "Municipal system" is specific to each municipality. Equation (2) implicitly assumes that FUNDEF resources received by the state are uniformly distributed among the state schools. While I cannot directly verify this assumption, the results (available upon request) remain qualitatively unchanged when restricting the sample to municipalities with few state schools.
} 
from and contributed to FUNDEF in 1998, respectively. $O_{i, 98}^{a}$ equals to $15 \%$ of four taxes and transfers (FPM/FPE, IPIExp, LC87/96, and ICMS) in 1998 and is the amount each municipality and state has effectively paid to FUNDEF in 1998. $I_{i, 98}^{a}$ are the values effectively received by municipalities and states from FUNDEF in 1998, which depend on all municipalities and states contributions in 1998 and the number of student enrolled in each system in 1997.

As discussed in Section 2, TOTIMPACT is potentially endogenous since it uses tax revenues from 1998 both in the calculations of $I_{i, 98}^{a}$ and $O_{i, 98}^{a}$. These tax revenues may be affected by unobserved macroeconomic variables that may also impact the share of private education, for example. In order to keep exclusively the exogenous source of variation due to FUNDEF reform, I instrument TOTIMPACT by TOTIMPACT ${ }^{s}$, the simulated impact of the reform. TOTIMPACT ${ }^{s}$ is calculated in the same way as TOTIMPACT, except that it uses the tax and transfer values for 1997. Thus, equation (2) is recalculated by using $I_{i, 97}^{a}$ and $O_{i, 97}^{a}$ instead of $I_{i, 98}^{a}$ and $O_{i, 98}^{a}$, respectively. $O_{i, 97}^{a}$ is equal to $15 \%$ of four taxes and transfers (FPM/FPE, IPIExp, LC87/96, and ICMS) in 1997 and $I_{i, 97}^{a}$ is calculated using total contributions with tax and transfer revenues from 1997 (and enrollment in 1997). That is, $I_{i, 97}^{a}$ is calculated based on the hypothetical total contribution of municipalities and states if FUNDEF reform had been in place in 1997.

As shown in Table 1, the average TOTIMPACT for the full sample is 0.271 with a standard deviation of 0.653. The average increases to 0.536 (with a standard deviation of 0.699 ) when considering the municipalities that were net recipients of FUNDEF, and decreases to -0.167 (with a standard deviation of 0.123 ) for those that were net contributors to FUNDEF. Thus, there is significant heterogeneity in treatment. As discussed in Section 2, even if the aggregate balance at the state level was zero for most states (Table A1), there was significant variation at the municipal level. Some municipalities lost resources with FUNDEF, but for others the positive impact was very significant. Note that the mean of FUNDEF for the full sample is positive for two reasons. First, some states received additional federal funds and therefore had a positive final balance. Second, by transferring resources from relatively wealthy to relatively poor municipalities, the final impact of the reform is positive since the gain of poorer municipalities is larger than the loss of richer municipalities in relative terms. This is exactly what is captured by equation (2).

\section{Results}

\subsection{The Impact of FUNDEF on the Share of Private Enrollment}

I estimate equation (1) using the financial impact of the FUNDEF reform (equation (2)) instrumented by the simulated impact of FUNDEF reform for all the municipalities with data available. In order to allow 
for a different impact on different primary school grades, I analyze each grade of primary school separately. The estimation results for Grades 1 to 4 using data for 1997 and 1999 are presented in Table 2. ${ }^{28}$

Column (1) of Table 2 shows that a standard deviation increase in TOTIM PACT (equal to 0.653) leads to a 0.46 percentage points decrease in the share of private enrollment in Grade 1. This corresponds to a $9.7 \%$ decrease in the share of private enrollment, given that the sample average is $4.7 \%$. The decrease is smaller and not statistically significant for Grades 2 to 4 (columns (2) to (4)). These results are in line with the intuition that there are costs associated with switching schools in the middle of a child's schooling path. Thus, there is evidence that the municipalities that benefited more from FUNDEF experienced a reduction in their share of private education in Grade 1.

Table 2 also presents the separate results for the municipalities that were net recipients (Panel B) and net contributors $($ Panel $C$ ) to FUNDEF. The results show that the overall negative effect is driven by the municipalities that were net recipients of FUNDEF. A one standard deviation increase in TOTIMPACT (equal to 0.699 in this sample) leads to a decrease of $10.4 \%$ in private school enrollment in Grade 1 . The increase is smaller (around 5\%) and significant only at the $10 \%$ level for Grades 2 and 4. A one standard deviation increase in TOTIMPACT is also associated with a $3 \%$ decline in the probability of having a private school for municipalities that were net recipients of FUNDEF. The impact of FUNDEF on the share of private education is reversed for net contributors to FUNDEF. A possible explanation is that net contributors to FUNDEF may have (at least partially) offset some of the negative impact of the reform by allocating a larger proportion of their overall budget. This would be consistent with the idea that it may be difficult to reduce the education budget, especially in the short term, given that much of the education expenditures have been pre-committed. While the data does not allow me to exploit the municipalities' reaction to FUNDEF precisely, Appendix A shows some evidence that net contributors seem to have offset the negative impact of the reform by increasing other sources of funding.

The results presented in Table 2 rely on the assumption that there are no pre-existing trends for municipalities that received more FUNDEF funding. This is particularly a concern since the municipalities that gained more from the reform were typically investing less per student than those that gained little or lost resources with the reform (within states, at least). If these municipalities were already in the process of improving school quality, my results would overestimate the impact of the reform. Conversely, if these municipalities were getting worse, then the outflow from private schools would have been larger than the estimation assumes, suggesting that I may be underestimating the impacts. In order to address this potential issue, I estimate equation (1) using data from 1996 and 1997, two years pre-FUNDEF reform. ${ }^{29}$ In this

\footnotetext{
${ }^{28}$ Restricting the sample to municipalities with a private school either in 1997 or 1999, or using 1997 and 2000 instead, yield similar results. I have also estimated the regression excluding the larger municipalities and obtained similar results.

${ }^{29}$ A drawback of using data from 1996 is that there was a large restructuring of municipalities between 1996 and 1997,
} 
placebo analysis, the measure TOTIMPACT corresponds to the one used previously in 1999. Table 3 shows that there were no pre-existing trends in municipalities that received more funding. Indeed, the impact of the FUNDEF reform on private enrollment between 1996 and 1997 is close to zero and never significant.

Another potential concern is that the threshold of net recipients and net contributors may be endogenous, being affected by macroeconomic shocks, among other factors. One can argue that this is more likely to affect municipalities that are closer to the threshold. In order to deal with this possibility, I performed a series of robustness checks that exclude $5 \%$ and $10 \%$ of the municipalities around the threshold. The results (not presented here, but available upon request) from the main specification (i.e., Table 2) remain qualitatively similar, suggesting that the previous estimated impacts on these sub-samples were not the result of this potential endogeneity issue.

Finally, the computation of the dependent variable assumes that there were no significant changes in the primary school-age population group due to migration or mortality between 1997 and 2000 (as discussed in Section 3). If there were changes in migration or mortality uncorrelated with the FUNDEF reform, this would not bias the results. I believe this is a safe assumption for mortality rates in the 7 to 10 age group, which are also quite small in Brazil. The probability of dying in this age group was on average $0.0319 \%$ in 1998 and $0.0326 \%$ in 1999. A more serious concern for the reliability of the results would be, for example, if parents decided to send their children to study in another municipality as a response to the FUNDEF reform. This would lead to the overestimation of the impact of the reform. Indeed, if public school quality in a given municipality increases (resp. decreases), this could lead to an increased (resp. decreased) enrollment from pupils from another municipality (not reflected in the denominator of the dependent variable). While the data available does not allow me to control for this possibility directly, I have re-estimated the model by excluding municipalities located in a metropolitan area (372 municipalities in the sample), where one would expect that more children could go to school in a municipality different from the municipality of residence. The results (not presented here) remain qualitatively and quantitatively very similar.

\subsection{The Impact of FUNDEF on Net School Attendance Rates}

Public school quality improvements caused by the FUNDEF reform could also increase net school attendance rates, by attracting to public schools children who were previously out of school. To test this prediction, I estimate equation (1) using net attendance rate as the dependent variable. Column (1) in Table 4 shows that FUNDEF had a positive impact on the net attendance rate. An increase of one standard deviation in TOTIMPACT is associated with an increase in net school attendance rates of 1.83 percentage points in

resulting in about 1,000 new municipalities. This does not, however, affect the main results of this paper, since municipalities can be reorganized only every four years. 
the full sample (column (1)) and 1.96 percentage points in the net recipients sample (column (2)). Given that the average net school attendance rates are equal to $91.8 \%$ and $90.0 \%$ in the full sample and for net recipients, these correspond to an increase of $2.0 \%$ and $2.2 \%$, respectively. Interestingly, the effect is not significant for the municipalities that were net contributors to FUNDEF.

\section{Conclusion}

In this paper, I investigate whether increases in public school expenditures lead to a reduction in the share of private education. Using the 1998 Brazilian FUNDEF reform as an exogenous variation in school expenditures, I show that this indeed seems to be the case, especially for Grade 1, and for the municipalities that gained resources with the reform. Regression results suggest that a standard deviation increase in the impact of FUNDEF reform, corresponding to approximately a $40 \%$ increase in the education budget, was associated with a $10.4 \%$ decrease in the share of private enrollment in Grade 1 for net recipients from FUNDEF. The effect is smaller for subsequent grades, where one can imagine switching costs are more significant. In addition, a standard deviation increase in the impact of the reform is also associated with a small increase in net school attendance rates.

These results emphasize the importance of accounting for an increase in the demand for public education following an increase in public school expenditures. They also suggest that the expansion of public school systems can be gradual, since most of the switching occurs in the first grade of primary education.

\section{References}

Alderman, Harold, Peter F. Orazem, and Elizabeth M. Paterno (2001) 'School quality, school cost, and the public/private school choices of low-income households in Pakistan.' Journal of Human Resources $36(2), 304-326$

Bommier, Antoine, and Sylvie Lambert (2000) 'Education demand and age at school enrollment in Tanzania.' Journal of Human Resources 35(1), 177-203

Câmara dos Deputados (2001) '[Final Report: Special subcomission for the analysis of irregularities of FUNDEF] Relatório Final: Subcomissão especial para análise de irregularidades do Fundo de Manutenção e Desenvolvimento do Ensino Fundamental e de Valorização do Magistério - FUNDEF.' Technical Report

Couch, Jim F, II Shughart, W. F, and Al L Williams (1993) 'Private school enrollment and public school performance.' Public Choice 76(4), 301-312

Epple, Dennis, and Richard E. Romano (1996) 'Ends against the middle: Determining public service provision when there are private alternatives.' Journal of Public Economics 62(3), 297-325

Estevan, Fernanda (2009) 'The quality of public education and private school enrollment: an assessment using Brazilian data.' Boston University - Department of Economics - The Institute for Economic Development Working Papers Series dp-185, Boston University - Department of Economics, April 
Filmer, Deon (2007) 'If you build it, will they come? School availability and school enrolment in 21 poor countries.' The Journal of Development Studies 43(5), 901-928

Glick, Peter, and David E. Sahn (2006) 'The demand for private schooling in Madagascar: Price, quality, and the choice between public and private providers.' Journal of Development Economics 79(1), 118-145

Goldhaber, Dan (1999) 'An endogenous model of public school expenditures and private school enrollment.' Journal of Urban Economics 46(1), 106-128

Handa, Sudhanshu (2002) 'Raising primary school enrolment in developing countries: The relative importance of supply and demand.' Journal of Development Economics 69(1), 103-128

Hanushek, Eric A. (2006) 'School Resources.' In 'Handbook of the Economics of Education' (New York: Elsevier) chapter 14, pp. 865-908

Hanushek, Eric A., and Steven G. Rivkin (2006) 'Teacher Quality.' In 'Handbook of the Economics of Education' (New York: Elsevier) chapter 18, pp. 1051-1078

Harbison, Ralph W., and Eric Alan Hanushek (1992) Education Performance of the Poor: Lessons from Rural Northeast Brazil (Published for the World Bank, Oxford University Press, Oxford, New York)

IBGE (2002) '[Public Expenditures by Functions] Despesas Públicas por Funções (in Portuguese).' IBGE website, http://www.ibge.gov.br/home/estatistica/economia/despesasfuncoes/default.shtm

Jimenez, Emmanuel, and Yasuyuki Sawada (2001) 'Public for private: The relationship between public and private school enrollment in the Philippines.' Economics of Education Review 20(4), 389-399

Kosec, Katrina (2011) 'Politics and preschool: The political economy of investment in pre-primary education.' World Bank Policy Research Working Paper 5647, 1-64

Lavy, Victor (1996) 'School supply constraints and children's educational outcomes in rural Ghana.' Journal of Development Economics 51(2), 291-314

Litschig, Stephan, and Kevin Morrison (2013) 'The Impact of Intergovernmental Transfers on Education Outcomes and Poverty Reduction.' American Economic Journal: Applied Economics 5(4), 206-240

Lockheed, Marlaine E., and Adriaan M. Verspoor (1991) Improving Primary Education in Developing Countries (Oxford University Press, Oxford, UK.)

Lucas, Adrienne, and Isaac M. Mbiti (2012) 'Access, Sorting, and Achievement: The Short-Run Effects of Free Primary Education in Kenya.' American Economic Journal: Applied Economics 4(4), 226-53

MEC (2002) '[98-02 FUNDEF Summary Report] Relatório Sintético FUNDEF 98-02 (in Portuguese).' http://mecsrv04.mec.gov.br/sef/fundef/pdf/balanco9802.pdf

Muralidharan, Karthik, and Michael Kremer (2008) 'Public and private school in rural India.' In 'School Choice International' (MIT Press) pp. 91-110

Paxson, Christina, and Norbert R. Schady (2002) 'The allocation and impact of social funds: Spending on school infrastructure in Peru.' World Bank Economic Review 16(2), 297-319

Stiglitz, Joseph E. (1974) 'The demand for education in public and private school systems.' Journal of Public Economics 3(4), 349-385

STN (1997) '[FINBRA Database] Base de Dados FINBRA (in Portuguese).' http://www.tesouro.fazenda. gov.br

_ (1998a) '[FINBRA Database] Base de Dados FINBRA (in Portuguese).' http://www.tesouro.fazenda. gov.br

_ (1998b) '[States and Municipalities Constitutional Transfers] Estados e Municípios Transferências Constitucionais (in Portuguese).' http://www3.tesouro.gov.br/estados_municipios/transferencias _constitucionais_novosite.asp 


\section{A Impact of FUNDEF on Total Education Budget}

In this appendix, I investigate the impact of FUNDEF reform on total expenditures for the municipal education system. I concentrate on the municipal system, since the data on total education expenditures for the state system is available from IBGE (2002) and does not correspond exactly to the one report by the Treasury for the municipalities. As discussed in Section 2, municipalities had to invest at least $25 \%$ of their total tax and transfers in primary and secondary education according to the 1988 Brazilian Constitution. With the implementation of the FUNDEF reform in 1998, the minimum $25 \%$ requirement was maintained. However, municipalities had to invest only $10 \%$ of their tax and transfers directly in their education system. The remaining $15 \%$ was directed to FUNDEF, a fund created inside each of the 26 Brazilian states, and redistributed back to the municipalities according to their enrollment levels.

Since the 1988 constitution and the FUNDEF reform only establish a minimum requirement, municipalities may invest additional resources in education. Moreover, there is the possibility that by adjusting the additional education expenditures, some municipalities may even offset the revenue effect of the reform. However, even in this extreme case, FUNDEF may still impact the education system by establishing a stricter control over the use of resources originated by the fund.

Precise data on municipal primary education expenditures does not exist for 1998. The best data available is "Total Public Education and Culture Expenditures," which includes expenditures on all education levels (primary, secondary, and tertiary) as well as culture. The data is based on municipalities' self-reporting and is not audited by the Treasury. It is also unclear whether the $15 \%$ paid to FUNDEF would count towards education expenditures or whether municipalities should only report the revenue they receive from FUNDEF and effectively invest in education. With all these caveats in mind, I estimate the effect of FUNDEF expenditures on total education expenditures by using the following equation:

$$
T E D_{i, 98}=\beta_{1} T A X_{i, 98}+\beta_{2} F U N D E F B A L A N C E_{i, 98}+\varepsilon_{i}
$$

where $T E D_{i, 98}$ is municipality $i$ 's "Total Public Education and Culture Expenditures," $T A X_{i, 98}$ is the total tax and transfer revenue, and FUNDEFBALANCE $E_{i, 98}$ is the actual FUNDEF balance. As before, I estimate the equation for the full sample, net recipients, and net contributors of the FUNDEF reform. ${ }^{30}$

The results are presented in Table A3. As expected, tax revenues are a strong predictor of education expenditures. For the full sample, on average $26 \%$ of tax revenues are converted into education expenditures, as shown in column (1), which is very close to the $25 \%$ mandated by the Constitution. There is also a positive

\footnotetext{
${ }^{30}$ To split the sample into net recipients and net contributors, I use the same criterion as in the rest of the paper. However, the "Total Public Education and Culture Expenditures" data is only available for 67\% of municipalities in 1998 (or 3,762 out of 5,517 municipalities).
} 
and strong relationship between the balance of FUNDEF and education expenditures. The coefficient of FUNDEFBALANCE is larger than one, indicating that, overall, municipalities do not seem to reduce additional expenditures as a response to FUNDEF.

Splitting the sample into net recipients and net contributors of FUNDEF reform provides further insights, as shown in Table A3. For net recipients, FUNDEF balance positively affects education expenditures (column (2)) and municipalities do not seem to reduce additional education expenditures as a result. Indeed, the coefficient of FUNDEFBALANCE is larger than one for net recipients of FUNDEF. Interestingly, there is evidence that net contributors may be using additional resources to compensate for FUNDEF loses (column (3)). The coefficient for $T A X$ shows that for $\mathrm{R} \$ 1$ of tax revenues, net contributors invest $\mathrm{R} \$ 0.29$ on education and culture. Moreover, the impact of FUNDEF balance on net contributors is not significant, indicating the presence of offsetting budgetary mechanisms.

These results shed light on the results previously obtained for net contributors. For that sample, the FUNDEF reform is not associated with a reduction of private school enrollment (Table 2), or affected net school attendance rates (Table 4). The evidence presented in this appendix indicates that this may be due to the fact that municipalities have offset the impact of FUNDEF reform by using additional budgetary resources.

\section{B Variables Definition}

Grade-Specific Primary School-Age Population: calculated by using the 2000 Population Census information on the number of children by age and considering the ideal age per grade and the year (1997 or 1999). For example, to compute the number of children aged $x$ in 1997, I use the number of children aged $x+3$ in 2000 . The assumption is that there were no significant population changes in the primary school-age group due to migration or mortality between 1997 and 2000.

Share of Children in High-Income Households: ratio of number of children living in high-income households to the population in the same age group. High income is defined as monthly per capita income of more than two times the national minimum wage in 2000 . The level was chosen so that about $13.5 \%$ of children would be in a high-income household, roughly matching the private school enrollment of $12.5 \%$. Using the 2000 Population Census data, I use the 7 to 9 age group for 1999, and the 10 to 14 age group for 1997, which is the only data available around the age group of interest. The assumption is that the income level of these age groups followed similar patterns between 1997 and 2000.

Total Population: estimates of total population by municipality for 1997 and 1999 provided by IBGE.

Employment Rate: ratio of the number of employees in December of a given year over the population aged 
15 to 64 in that municipality. The data on the number of employees is from the Annual Social Information Report that includes the universe of formal employees in all branches of economic activity. The population aged 15 to 64 is estimated using the 2000 Population Census. For 1997, I use the number of individuals aged 18 to 67 in 2000 and for 1999, aged 16 to 65 in 2000.

Net Attendance Rate: ratio of number of children aged 7 to 9 attending school to the population reporting schooling status in the same age group, available in the 1996 Population Count and 2000 Population Census.

Contribution to FUNDEF: each municipality/ state contributes $15 \%$ of four taxes and transfers (FPM/FPE, IPIExp, LC87/96, and ICMS). For the municipalities, data on the first three can be obtained from the Brazilian National Treasury in STN (1998b). ICMS is collected by the states, but $25 \%$ of it is transferred to their municipalities. Information on this transfer is provided by some State Treasuries. When this information was not available, I used similar data provided by the National Treasury in STN (1998a). This data is missing for some municipalities and therefore the financial impact of the FUNDEF reform cannot be calculated for them. For the states, the source is MEC (2002) and corresponds to the data shown in Table A1.

Revenue from FUNDEF: In 1998, the information is available from the National Treasury in STN (1998b) for the municipalities and in MEC (2002) for the states (and in Table A1).

Simulated FUNDEF variable: To calculate the simulated FUNDEF variable, I have used data on the four taxes and transfers (FPM/FPE, IPIExp, LC87/96, and ICMS) for 1997, available in the same databases mentioned above.

Total Public Education Expenditures: for the municipalities, total public education expenditures is available from the Brazilian National Treasury in STN (1997), and for the states in IBGE (2002). The municipal data includes expenditures for pre-primary, primary, secondary, and tertiary education level and culture. The state data includes pre-primary, primary, and secondary levels. Since the data for municipalities and states comes from different databases, they are not directly comparable.

Age-by-grade distortion rate: proportion of students who are two years older than the normal age for each grade. The information on student ages is provided in the 1999 School Census (but not in the 1997 School Census). 


\section{Tables and Figures}

Table 1: Descriptive Statistics

\begin{tabular}{|c|c|c|c|c|c|c|c|c|c|}
\hline & \multicolumn{3}{|c|}{ Full Sample } & \multicolumn{3}{|c|}{ Net Recipients } & \multicolumn{3}{|c|}{ Net Contributors } \\
\hline & 1997 & 1999 & Diff. & 1997 & 1999 & Diff. & 1997 & 1999 & Diff. \\
\hline \multicolumn{10}{|c|}{ A.1. Share of Private Enrollment } \\
\hline Grade 1 & $\begin{array}{c}0.047 \\
(0.090)\end{array}$ & $\begin{array}{c}0.043 \\
(0.070)\end{array}$ & $-9 \% * *$ & $\begin{array}{c}0.054 \\
(0.094)\end{array}$ & $\begin{array}{l}0.048 \\
(0.071)\end{array}$ & $-11 \% * *$ & $\begin{array}{l}0.036 \\
(0.082)\end{array}$ & $\begin{array}{c}0.034 \\
(0.068)\end{array}$ & $-6 \%$ \\
\hline Grade 2 & $\begin{array}{c}0.042 \\
(0.077)\end{array}$ & $\begin{array}{l}0.040 \\
(0.066)\end{array}$ & $-5 \%$ & $\begin{array}{l}0.047 \\
(0.077)\end{array}$ & $\begin{array}{c}0.045 \\
(0.067)\end{array}$ & $-4 \%$ & $\begin{array}{l}0.034 \\
(0.077)\end{array}$ & $\begin{array}{c}0.031 \\
(0.064)\end{array}$ & $-9 \%$ \\
\hline Grade 3 & $\begin{array}{c}0.040 \\
(0.073)\end{array}$ & $\begin{array}{c}0.036 \\
(0.062)\end{array}$ & $-10 \% * *$ & $\begin{array}{l}0.044 \\
(0.073)\end{array}$ & $\begin{array}{c}0.041 \\
(0.062)\end{array}$ & $-7 \% *$ & $\begin{array}{c}0.033 \\
(0.072)\end{array}$ & $\begin{array}{c}0.029 \\
(0.060)\end{array}$ & $-12 \%$ \\
\hline Grade 4 & $\begin{array}{c}0.037 \\
(0.071)\end{array}$ & $\begin{array}{l}0.035 \\
(0.060)\end{array}$ & $-5 \% * *$ & $\begin{array}{c}0.041 \\
(0.070)\end{array}$ & $\begin{array}{c}0.039 \\
(0.060)\end{array}$ & $-5 \%$ & $\begin{array}{c}0.031 \\
(0.072)\end{array}$ & $\begin{array}{c}0.028 \\
(0.058)\end{array}$ & $-10 \%$ \\
\hline \multicolumn{10}{|c|}{ A.2. Presence of Private School } \\
\hline Private School & $\begin{array}{c}0.405 \\
(0.491)\end{array}$ & $\begin{array}{c}0.429 \\
(0.495)\end{array}$ & $6 \% * *$ & $\begin{array}{c}0.473 \\
(0.499)\end{array}$ & $\begin{array}{c}0.498 \\
(0.500)\end{array}$ & $5 \% *$ & $\begin{array}{c}0.292 \\
(0.455)\end{array}$ & $\begin{array}{c}0.314 \\
(0.464)\end{array}$ & $8 \%$ \\
\hline $\begin{array}{l}\text { A.3. Population data } \\
\text { Share of Children in }\end{array}$ & & & & & & & & & \\
\hline High-Income Households & $\begin{array}{c}0.095 \\
(0.079)\end{array}$ & $\begin{array}{c}0.085 \\
(0.073)\end{array}$ & $-11 \% * * *$ & $\begin{array}{c}0.084 \\
(0.077)\end{array}$ & $\begin{array}{c}0.074 \\
(0.070)\end{array}$ & $-12 \% * * *$ & $\begin{array}{c}0.113 \\
(0.079)\end{array}$ & $\begin{array}{c}0.102 \\
(0.076)\end{array}$ & $-10 \% * * *$ \\
\hline Population & $\begin{array}{c}0.321 \\
(1.953)\end{array}$ & $\begin{array}{c}0.330 \\
(1.979)\end{array}$ & $3 \%$ & $\begin{array}{l}0.388 \\
(2.333)\end{array}$ & $\begin{array}{l}0.398 \\
(2.358)\end{array}$ & $3 \%$ & $\begin{array}{c}0.211 \\
(1.051)\end{array}$ & $\begin{array}{c}0.217 \\
(1.086)\end{array}$ & $3 \%$ \\
\hline Mean Earnings & $\begin{array}{c}0.302 \\
(0.128)\end{array}$ & $\begin{array}{c}0.322 \\
(0.273)\end{array}$ & $7 \% * * *$ & $\begin{array}{l}0.314 \\
(0.140)\end{array}$ & $\begin{array}{c}0.333 \\
(0.338)\end{array}$ & $6 \% * * *$ & $\begin{array}{c}0.282 \\
(0.102)\end{array}$ & $\begin{array}{c}0.303 \\
(0.095)\end{array}$ & $7 \% * * *$ \\
\hline Employment Rate & $\begin{array}{c}0.127 \\
(0.121)\end{array}$ & $\begin{array}{c}0.131 \\
(0.121)\end{array}$ & $3 \% *$ & $\begin{array}{c}0.117 \\
(0.127)\end{array}$ & $\begin{array}{c}0.120 \\
(0.127)\end{array}$ & $3 \%$ & $\begin{array}{c}0.143 \\
(0.108)\end{array}$ & $\begin{array}{c}0.150 \\
(0.108)\end{array}$ & $5 \% *$ \\
\hline Net School & & & & & & & & & \\
\hline Attendance Rate & $\begin{array}{c}0.918 \\
(0.079)\end{array}$ & $\begin{array}{c}0.948 \\
(0.067)\end{array}$ & $3 \% * * *$ & $\begin{array}{c}0.900 \\
(0.084)\end{array}$ & $\begin{array}{c}0.937 \\
(0.069)\end{array}$ & $4 \% * * *$ & $\begin{array}{c}0.947 \\
(0.058)\end{array}$ & $\begin{array}{c}0.965 \\
(0.059)\end{array}$ & $2 \% * * *$ \\
\hline A.4. FUNDEF reform & & & & & & & & & \\
\hline TOTIMPACT & $\begin{array}{c}0 \\
(0)\end{array}$ & $\begin{array}{c}0.271 \\
(0.653)\end{array}$ & $* * *$ & $\begin{array}{c}0 \\
(0)\end{array}$ & $\begin{array}{c}0.536 \\
(0.699)\end{array}$ & $* * *$ & $\begin{array}{c}0 \\
(0)\end{array}$ & $\begin{array}{l}-0.167 \\
(0.123)\end{array}$ & $* * *$ \\
\hline TOTIMPACT & $\begin{array}{c}0 \\
(0)\end{array}$ & $\begin{array}{c}0.387 \\
(0.858)\end{array}$ & $* * *$ & $\begin{array}{c}0 \\
(0)\end{array}$ & $\begin{array}{c}0.719 \\
(0.938)\end{array}$ & $* * *$ & $\begin{array}{c}0 \\
(0)\end{array}$ & $\begin{array}{l}-0.162 \\
(0.120)\end{array}$ & $* * *$ \\
\hline Observations & 4,289 & 4,289 & & 2,675 & 2,675 & & 1,614 & 1,614 & \\
\hline
\end{tabular}

Notes: ${ }^{*}$ significant at $10 \%,{ }^{* *}$ significant at $5 \%,{ }^{* * *}$ significant at $1 \%$. Standard deviations are in parentheses. All the variables are calculated at the municipal level. The 'Net School Attendance Rate' data is from 1996 and 2000. Population is measured in 100,000s and Mean Income is measured in 1,000s Brazilian reais. Sources: 1997-1999 School Census, 1996 Population Count, 2000 Population Census and 1997-1999 RAIS. 
Table 2: Impact of FUNDEF on Share of Private Education 1997 and 1999: 2SLS Regression

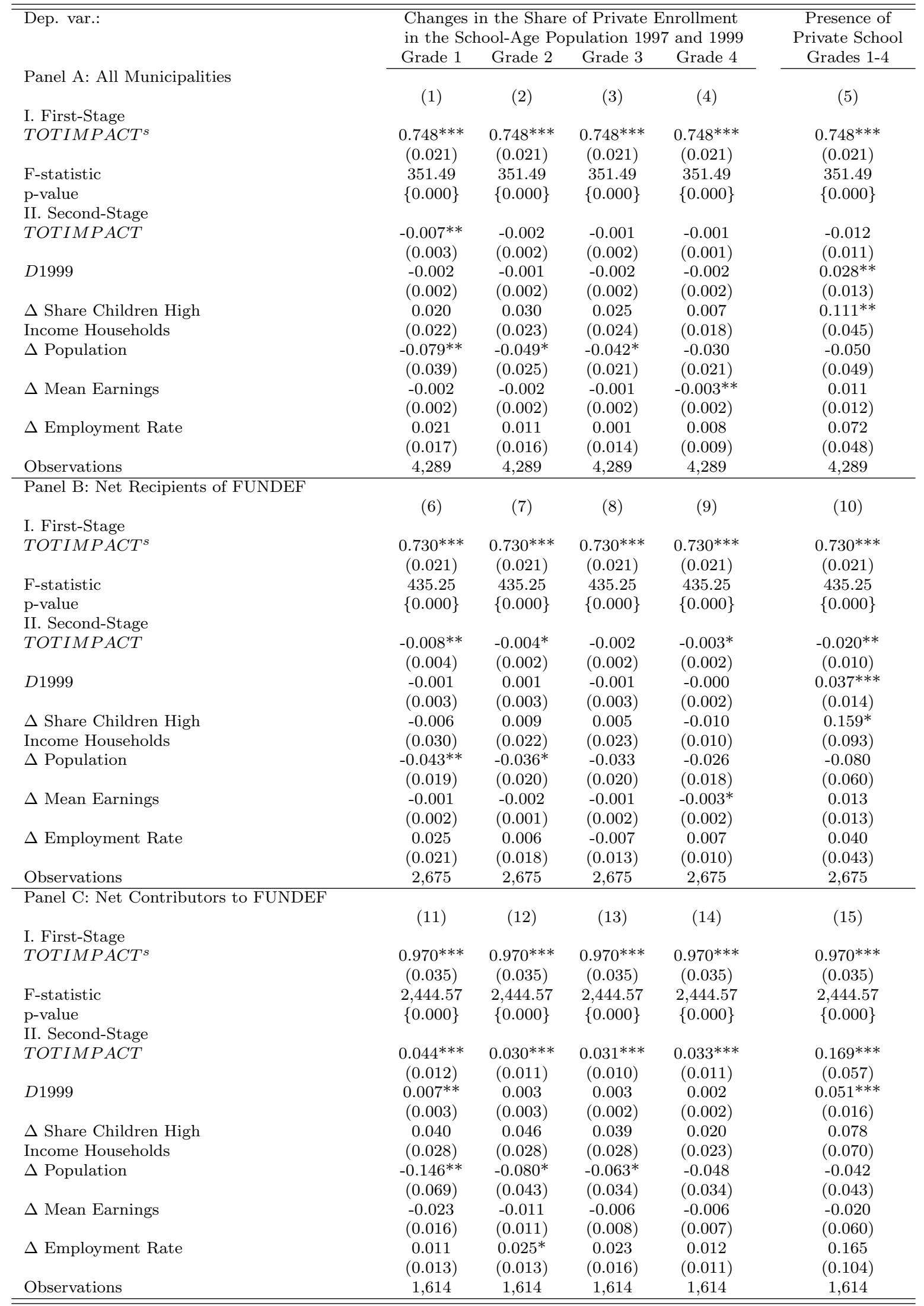

Notes: Robust standard errors clustered at the state level are in parentheses. ${ }^{*}$ significant at $10 \%,{ }^{* *}$ significant at $5 \%, * * *$ significant at $1 \%$. The reported $\mathrm{F}$-statistics are from a test of significance of the excluded instrument. All municipalities with data available. 
Table 3: Placebo Analysis: Impact of FUNDEF on Share of Private Education 1996 and 1997: 2SLS Regression

\begin{tabular}{lcccc}
\hline \hline Dep. var.: & \multicolumn{4}{c}{ Changes in the Share of Private Enrollment } \\
& in the School-Age Population 1996 and 1997 \\
& Grade 1 & Grade 2 & Grade 3 & Grade 4 \\
\hline I. First-Stage & $(1)$ & $(2)$ & $(3)$ & $(4)$ \\
TOT IMPACT & & & & \\
& $0.748^{* * *}$ & $0.748^{* * *}$ & $0.748^{* * *}$ & $0.748^{* * *}$ \\
F-statistic & $(0.021)$ & $(0.021)$ & $(0.021)$ & $(0.021)$ \\
p-value & 664.63 & 664.63 & 664.63 & 664.63 \\
II. Second-Stage & $\{0.000\}$ & $\{0.000\}$ & $\{0.000\}$ & $\{0.000\}$ \\
TOTIMPACT & & & & \\
& 0.001 & 0.001 & 0.001 & 0.001 \\
D1997 & $(0.002)$ & $(0.002)$ & $(0.001)$ & $(0.001)$ \\
& $-0.005^{* *}$ & $-0.003^{* *}$ & -0.001 & 0.000 \\
Observations & $(0.002)$ & $(0.001)$ & $(0.001)$ & $(0.001)$ \\
\hline \hline
\end{tabular}

Notes: Robust standard errors clustered at the state level are in parentheses. ${ }^{*}$ significant at $10 \%,{ }^{*}$ significant at $5 \%,{ }^{* * *}$ significant at $1 \%$. The reported F-statistics are from a test of significance of the excluded instrument. All municipalities with data available.

Table 4: Impact of FUNDEF on Net School Attendance Rate: 2SLS Regression

\begin{tabular}{lccc}
\hline \hline Dep. var.: & \multicolumn{3}{c}{ Changes in the Net Attendance Rate 1996 and 2000 } \\
\hline & All Municipalities & Net Recipients & Net Contributors \\
& $(1)$ & $(2)$ & $(3)$ \\
I. First-Stage & & & \\
TOT IMPACT & $\left(0.748^{* * *}\right.$ & $0.729^{* * *}$ & $0.970^{* * *}$ \\
& 406.05 & $(0.021)$ & $(0.035)$ \\
F-statistic & $\{0.000\}$ & 529.70 & $2,747.67$ \\
p-value & & $\{0.000\}$ & $\{0.000\}$ \\
II. Second-Stage & $0.028^{* * *}$ & $0.028^{* * *}$ & 0.014 \\
TOTIMPACT & $(0.002)$ & $(0.002)$ & $(0.012)$ \\
& $0.023^{* * *}$ & $0.023^{* * *}$ & $0.021^{* * *}$ \\
D1999 & $(0.004)$ & $(0.005)$ & $(0.003)$ \\
& $-0.081^{* * *}$ & $-0.107^{* *}$ & $-0.035^{* * *}$ \\
$\Delta$ Population & $(0.018)$ & $(0.043)$ & $(0.009)$ \\
& -0.000 & 0.001 & $-0.036^{*}$ \\
$\Delta$ Mean Earnings & $(0.006)$ & $(0.004)$ & $(0.019)$ \\
$\Delta$ Employment Rate & -0.028 & -0.044 & 0.018 \\
& $(0.023)$ & $(0.037)$ & $(0.013)$ \\
Observations & & & 1,614 \\
\hline \hline
\end{tabular}

Notes: Robust standard errors clustered at the state level are in parentheses. ${ }^{*}$ significant at $10 \%,{ }^{* *}$ significant at $5 \%,{ }^{* * *}$ significant at $1 \%$. All municipalities with data available. 


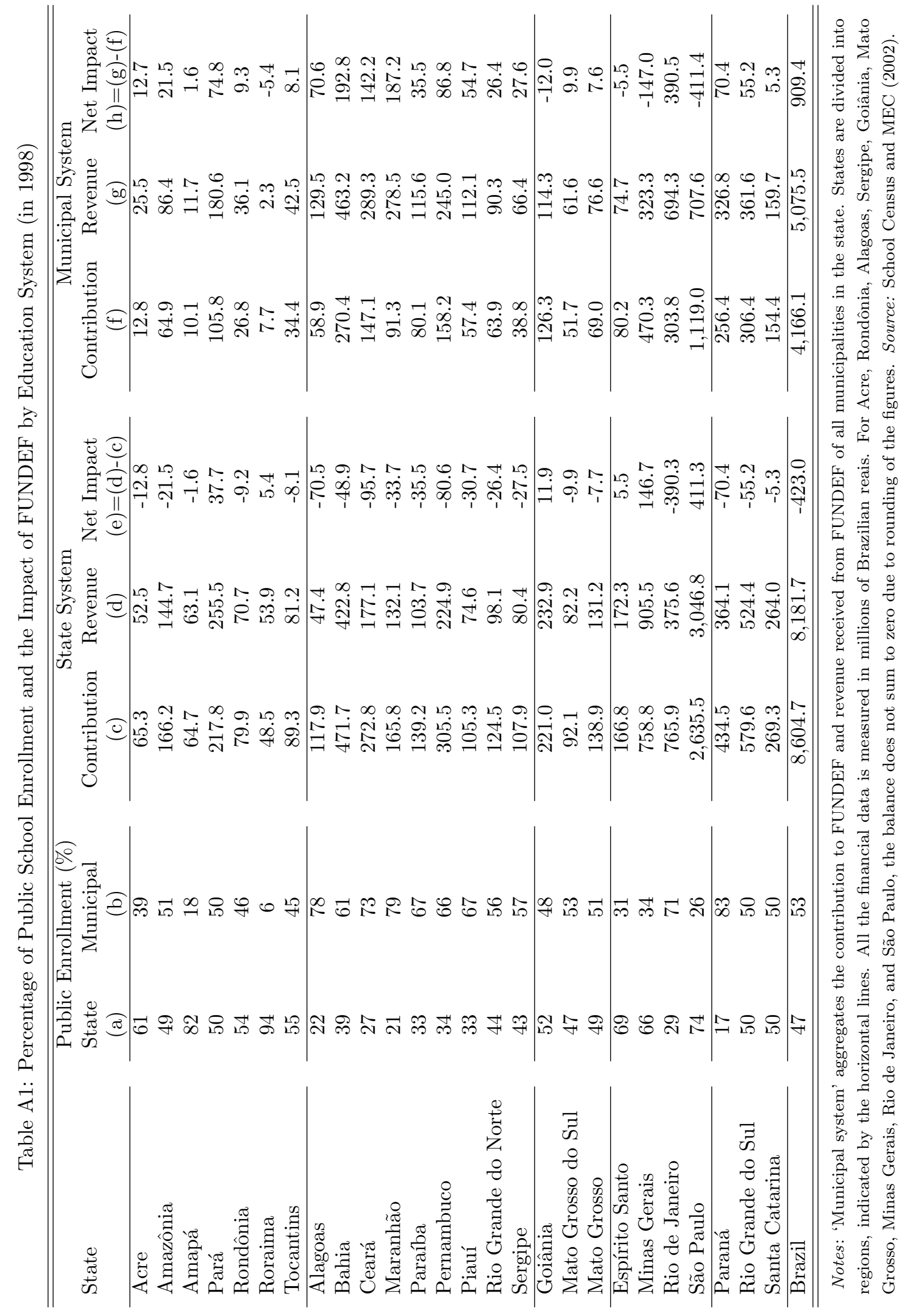


Table A2: Primary Education in Brazil

\begin{tabular}{|c|c|c|c|c|c|c|}
\hline & \multicolumn{2}{|c|}{ Total } & \multicolumn{2}{|c|}{ Public } & \multicolumn{2}{|c|}{ Private } \\
\hline & 1997 & 1999 & 1997 & 1999 & 1997 & 1999 \\
\hline & Before & After & Before & After & Before & After \\
\hline & FUNDEF & FUNDEF & FUNDEF & FUNDEF & FUNDEF & FUNDEF \\
\hline $\begin{array}{l}\text { Number of } \\
\text { Primary Schools }\end{array}$ & 188,879 & 174,238 & 172,326 & 156,980 & 16,553 & 17,258 \\
\hline $\begin{array}{l}\text { Enrollment in } \\
\text { Primary Schools }\end{array}$ & $20,568,128$ & $20,939,076$ & $18,606,189$ & $19,220,984$ & $1,961,939$ & $1,718,092$ \\
\hline $\begin{array}{l}\text { Primary School- } \\
\text { Age Population }\end{array}$ & $13,787,236$ & $13,276,987$ & - & - & - & \\
\hline $\begin{array}{l}\text { Gross } \\
\text { Enrollment Rate }\end{array}$ & 149.2 & 157.7 & - & - & - & \\
\hline
\end{tabular}

Table A3: Impact of FUNDEF on Total Education Expenditures

\begin{tabular}{|c|c|c|c|}
\hline \multirow[t]{2}{*}{ Dep. Var.: } & \multicolumn{3}{|c|}{ Total Education and Culture Expenditures 1998} \\
\hline & $\begin{array}{l}\text { All Municipalities } \\
(1)\end{array}$ & $\begin{array}{c}\text { Net Recipients } \\
(2)\end{array}$ & $\begin{array}{c}\text { Net Contributors } \\
(3)\end{array}$ \\
\hline$T A X$ & $\begin{array}{c}0.264^{* * *} \\
(0.008)\end{array}$ & $\begin{array}{c}0.249^{* * *} \\
(0.006)\end{array}$ & $\begin{array}{c}0.293^{* * *} \\
(0.042)\end{array}$ \\
\hline$F U N D E F B A L A N C E$ & $\begin{array}{c}1.364^{* * *} \\
(0.417)\end{array}$ & $\begin{array}{c}1.638^{* * *} \\
(0.307)\end{array}$ & $\begin{array}{l}-0.702 \\
(1.275)\end{array}$ \\
\hline Observations & 3,762 & 2,209 & 1,553 \\
\hline R-squared & 0.971 & 0.981 & 0.914 \\
\hline
\end{tabular}

